\title{
NOTA PRELIMINAR A LA VERSION ESPAÑOLA
}

Cuando una obra alcanza la difusión universal que significan 18 ediciones-número logrado por el "Auskunftsbuch für die Chemische Industrie»-no es preciso esforzarse en otro tipo de presentación ponderativa. El éxito se confirma si, como en este caso, la obra ha sido traducida a varios idiomas.

La versión española de la obra de Blücher llega, en efecto, cuando en su idioma de origen ha alcanzado un punto tal de plena madurez que resulta casi supérfluo encarecer su elevada significación y utilidad. Las sucesivas revisiones y correcciones han permitido escalar un nivel de perfección, único en su género, en el que la absoluta modernidad de presentación y tratamiento se conjuga, admirablemente, con la total carencia de material supérfluo y de repeticiones innecesarias.

Con una absoluta objetividad, los diversos autores que han colaborado a lo largo de los años en la realización de la Enciclopedia de Blücher se han impuesto, en efecto, como una tarea paralela a la de su sistemática modernización, la supresión inmediata de las referencias a temas superados y la poda continua de las consideraciones y detalles de menor valor, hasta lograr que su engrandecimiento y perfección no corriese paralelo con un incremento desmesurado de tamaño. La información básica, como los detalles técnicos y estadísticos, alcanzan así una ponderación y equilibrio sorprendentes por su profundidad en una obra de esta magnitud.

La penetración de la Tecnología Química en el ámbito de la Industria ha llegado a ser tan completa en el transcurso de los pasados lustros, que difícilmente puede concebirse un técnico industrial de cualquier rama, al que no se planteen, más o menos directamente, problemas de índole química y que incluso no precise utilizar con propiedad la peculiar terminología de esta ciencia. Si esto es un hecho en lo que se refiere a las actividades industriales, no es menos cierto que un amplísimo sector del comercio y hasta casi cualquier hombre culto, requiere a cada paso información concreta y fehaciente sobre las más heterogéneas cuestiones que con la Química se relacionan.

La dificultad para alcanzar las fuentes adecuadas de información crece, sin embargo, en razón directa del alejamiento que, en relación con la Química, presente la formación previa de cada individuo. De aquí que una obra como el Manual de Blücher pueda considerarse como básica en cualquier biblioteca, puesto que si rinde inestimables servicios al profesional químico o técnico, en cualquiera de sus especialidades, no es menos valiosa su consulta para el profano, quien, en la actuali- 
dad, no puede soslayar el enfrentarse con términos o cuestiones propias del campo de la Química.

La 18.a edición presenta como novedad, respecto a sus anteriores, cuanto se refiere a operativa quimica y a la más moderna aportación científica así de teorías y descubrimientos, como de nuevos productos y sus aplicaciones.

Como obra de primera consulta constituye la presente "Enciclopedia de Química" un auxiliar inestimable que jamás defrauda a quien lo maneja. Reunido en un solo volumen manejable, ofrece conjuntamente definiciones, clasificaciones, características y constantes físicas y químicas de toda clase de sustancias y drogas, esquemas de producción y procesos industriales, reseña de materiales y maquinaria, estadísticas, etc. Es, a la vez, un diccionario técnico, un manual de consulta de datos numéricos y una condensada enciclopedia. La condensación no ha sido, sin embargo, óbice para que se conceda la necesaria extensión a todas aquellas cuestiones de interés primario que la precisan. $\mathrm{Y}$ a título de ejemplo pueden cotejarse, los extensos apartados dedicados a "Productos Intermedios" o "Colorantes», de perfecta sistematización y tratamiento. Esta precisión está lograda incluso en las entradas más concisas, que en ningún caso adquieren el carácter de mención superficial.

Por lo que respecta, concretamente, a la edición española, el lector podrá darse cuenta de las múltiples dificultades vencidas en el dispositivo alfabético de ordenación de los apartados, dificultades nacidas, en gran parte, de la diferente índole constructiva de los idiomas alemán y español, y que directamente afectaban a la rapidez de localización de una determinada materia. Ello ha obligado a una cuidada estimación del término clave elegido para alfabetizar, lo que unido a la duplicación de llamada, en caso necesario, facilitará el manejo de la obra. La única variación, en algún caso, respecto del texto alemán ha sido reunir en un solo apartado lo referente a términos que, en la versión original, aparecían separados por las razones idiomáticas antes aludidas.

Recomendamos al lector, como consecuencia de cuanto queda dicho, que el término que desee hallar lo busque en el cuerpo general de la obra, dentro de su correspondiente ordenación alfabética, considerando, en el caso de no hallarlo, la posibilidad de una sinonimia o de un término más genérico que englobe en su tratamiento al que concretamente se consulte. Para facilitar hasta el máximo esta tarea se inserta al fin de la obra un Registro CoMpLEMENTARIo, totalmente reelaborado para la versión española. En él se recogen todas las sinonimias advertidas, así como las subsecciones, denominaciones comerciales, e incluso los términos subordinados y menciones ocasionales, siempre que carezcan de apartado propio y que su interés lo justifique. Este Registro Complementario viene así a completar la información inmediata, y consideramos que ha de constituir un valioso auxiliar para la obtención de un mayor fruto en la consulta de la obra, en particular por el público no especialísta.

El respeto por el original alemán ha impuesto la conveniencia de no incrementar la ya copiosa bibliografía que incluye la obra, salvo en alguna ocasional mención 
a obras españolas. En casi todos los casos, la bibliografía incluye una primera mención a una serie de obras básicas bien conocidas, tales como la de Beilstein para la Química Orgánica, la de Gmelin para la Inogárnica, la Enciclopedia Ullmann (3.a Edición) para los aspectos técnicos, la Tecnología Química de Winnacker-Weingaertner, el Tratado de Farmacia Práctica de Hager, etc. Aun presentando una lógica tendencia a las fuentes de información germanas, la bibliografía incluye, sin embargo, un gran número de las más destacadas publicaciones en todo el ámbito mundial, sirviendo así de inestimable complemento orientador.

El esmero con que ha sido realizada la tarea, así como la cuidada traducción, a cargo de destacados especialistas, nos hace confiar en que la versión española no desmerecerá del original alemán y como éste podrá ser calificado de universalmente útil». 
